\title{
A Experiência da Rede PETRO-RS: uma Estratégia para o Desenvolvimento das Capacidades Dinâmicas
}

\author{
Moisés Villamil Balestro \\ José Antônio Valle Antunes Júnior \\ Marcelo Carvalho Lopes \\ Ivan de Pellegrin
}

\begin{abstract}
Resumo
Com base na experiência pioneira no Brasil de uma rede de empresas fornecedoras da cadeia de suprimento da indústria do petróleo e gás localizada no Rio Grande do Sul - a Rede PETRO-RS, o artigo sustenta que a organização em torno de uma rede voltada para o mercado e o desenvolvimento tecnológico contribui para os recursos das organizações, subsidiando o desenvolvimento das capacidades dinâmicas. Desta forma, o artigo argumenta que a formação de uma rede que estimule a cooperação entre os atores envolvidos no processo de inovação tecnológica e que potencie os recursos internos e externos das empresas constitui uma estratégia para o desenvolvimento das capacidades dinâmicas. Resultado de uma iniciativa do Governo do Estado, a Rede PETRO-RS reúne mais de 100 empresas, além de extensa gama de outros atores como universidades, centros de pesquisa, fornecedores, clientes (com destaque para a PETROBRÁS) e órgãos governamentais. Dada a diversidade de atores envolvidos e sua forte vinculação com a inovação tecnológica na cadeia de suprimento da indústria de petróleo e gás, a experiência da Rede PETRO-RS constitui um exemplo da construção de capacidades associada à formação de uma estratégia coletiva ou interorganizacional.
\end{abstract}

Palavras-chaves: capacidades dinâmicas; rede; inovação tecnológica; indústria do petróleo e gás.

\begin{abstract}
Based upon a pioneer experience in Brazil of a suppliers network from the oil and gas industry supply chain located in Rio Grande do Sul - Rede PETRO-RS, it is argued that the building of a business network to break into new markets and carry out technological development contribute to the organization resources and to the development of dynamic capabilities. Thus, the article poses that the formation of a network stimulating cooperation among the different actors involved in the technological innovation to best use internal and external resources outlines a strategy for the development of dynamic capabilities. Resulting from a initiative from the State Government from Rio Grande do Sul, Rede PETRO-RS gathers more than 100 companies, besides other actors such as universities, research centers, suppliers, customers (especially the case of PETROBRÁS) and Government bodies. Due to the wide range of actors and their strong link to technological innovation in the oil and gas supply chain, Rede PETRO-RS is seen as an example of the formation of a collective or interorganizational strategy.
\end{abstract}

Key words: dynamic capabilities; network; technological innovation; oil and gas industry. 


\section{INTRODUÇÃO}

Em um ambiente competitivo em que a inovação se torna a principal fonte de vantagem competitiva, o desenvolvimento da capacidade tecnológica das empresas exige uma quantidade de recursos cada vez maior. Conforme Dosi (1988), a inovação está cada vez mais baseada na ciência, fazendo com que a pesquisa e o desenvolvimento de novos produtos sejam mais intensivos em conhecimento. Devido ao caráter complexo e fragmentado do conhecimento necessário à inovação, torna-se muito difícil o seu desenvolvimento no interior das fronteiras de uma única empresa, o que faz com que o tema da cooperação interempresarial se torne parte do cotidiano das empresas, sejam elas grandes ou pequenas. No caso de uma indústria intensiva em capital e com forte conteúdo tecnológico como a do petróleo e gás, os processos que conduzem às inovações tecnológicas são muito mais complexos, fazendo com que a inovação seja resultado da interação de vários outros atores.

A partir do crescimento das relações de cooperação interorganizacional com o objetivo de alavancar a capacidade tecnológica das empresas, surgem novas configurações organizacionais. Assim, mais do que um arranjo temporário para a solução de problemas ad hoc nas áreas de produção ou marketing, as novas configurações na forma de redes de empresas podem constituir uma resposta estratégica para elevar a capacidade inovativa das empresas. Diferentemente das relações de cooperação entre duas empresas, as redes constituem relações entre várias empresas, sejam elas do mesmo setor ou situadas ao longo de uma cadeia produtiva. No caso deste artigo, o conceito de rede aplicado à experiência da Rede PETRO-RS é abrangente, incluindo outros atores, como universidades, centros tecnológicos, instituições financeiras e Governo do Estado.

Na ótica do comportamento estratégico, as empresas formam configurações cooperativas, a fim de maximizar a sua lucratividade de longo prazo e melhorar a sua posição competitiva. As empresas se envolvem em atividades cooperativas como meio de atingir objetivos estratégicos gerais. A alta gerência escolherá parceiros e tipos de atividades cooperativas que possam melhorar a posição competitiva da empresa (McGee, Dowling e Megginson, 1995). Assim, as parcerias e outras formas de colaboração são motivadas, entre outras coisas, pela necessidade de atingir maior eficiência na produção, partilhar os crescentes riscos presentes nas atividades de P\&D, ganhar acesso a novos mercados e habilidades e lograr maior compressão de tempo no desenvolvimento de novos produtos e na busca por novas oportunidades tecnológicas (Lorenzoni e Lipparini, 1999). 
Com o objetivo de examinar o papel de uma rede voltada à cadeia de suprimento da indústria do petróleo e gás para o desenvolvimento de competências e capacidades dinâmicas das empresas, o artigo está dividido em cinco partes: uma revisão sobre os conceitos de competência e capacidades dinâmicas; a rede e seu papel para o desenvolvimento de competências; experiência internacional semelhante; apresentação e análise da experiência da Rede PETRO-RS; conclusão.

\section{Competências e Capacidades Dinâmicas}

Conforme o artigo seminal de Prahalad e Hamel (1990), as competências essenciais representam o aprendizado coletivo na organização, especialmente no que diz respeito a como coordenar as diversas habilidades de produção e integrar as múltiplas correntes da tecnologia. As competências essenciais oferecem acesso a uma ampla variedade de mercados, contribuem de maneira significativa para os benefícios percebidos dos clientes do produto final e são difíceis de serem imitadas. A competência essencial também requer profundo comprometimento em trabalhar além das fronteiras organizacionais (Prahalad e Hamel, 1990). De forma mais genérica, as competências são capacidades para estruturar e orientar conjuntos de recursos para fins produtivos que potencialmente forneçam à empresa uma vantagem competitiva (Christiensen, 1996). Trata-se de capacidade gerencial de ordem superior da empresa para mobilizar, harmonizar e desenvolver recursos e capacidades para criar valor e vantagem competitiva.

Elas são o resultado combinado do aprendizado interno com o aprendizado por absorção de fontes externas (Christiensen, 1996). A força da aprendizagem por absorção (absorptive learning) da empresa depende das suas capacidades internas, da qualidade e da relevância do conhecimento externo, da estrutura das suas relações e do ambiente externo ou de sua rede externa, como veremos mais adiante. Primeiramente considerada por Cohen e Levinthal (1990), a aprendizagem por absorção não se refere apenas à aquisição ou assimilação de informação pela organização, mas também à sua habilidade em explorar essa mesma informação (Cohen e Levinthal, 1990). Neste sentido, a aprendizagem por absorção também depende dos recursos de cada empresa. Pode ser considerado um recurso estratégico a capacidade de coordenar recursos dentro e fora da organização, a partir da constituição de uma rede ativa de relacionamentos internos e externos, uma vez que isso fortalece a capacidade de absorção (Cohen e Levinthal, 1990). Pode-se argumentar que organizações constituidas em rede que lhes permita acesso a uma diversidade maior de informação e conhecimento, 
terão capacidade de absorção maior do que seus concorrentes. Isto porque as redes permitem interconectividade maior na qual os recursos (tangíveis ou intangíveis) são mais facilmente disponibilizados e internalizados. No caso deste artigo, foi possível constatar, por meio de informações qualitativas obtidas nas entrevistas, uma relação entre maior aprendizado por absorção das empresas com a sua integração na Rede PETRO-RS.

Ao falar sobre as competências organizacionais, Dosi e Marengo (1994) também partilham da opinião de que trajetórias organizacionais e tecnológicas diversas contribuem para a maior capacidade inovativa por meio da tensão entre exploração de novas possibilidades e utilização das possibilidades existentes. A seguir, a fim de enriquecer o conceito de competência, será apresentada a noção de capacidades dinâmicas.

As capacidades dinâmicas (Teece, Pisano e Shuen, 1997) se referem à capacidade de renovar competências para atingir congruência com o ambiente empresarial em mutação. O termo capacidades enfatiza o papel da gestão estratégica em adaptar, integrar e reconfigurar habilidades organizacionais internas e externas, recursos e competências funcionais para satisfazer às exigências de um ambiente em mutação. Da mesma forma que as competências essenciais, as capacidades dinâmicas têm como pressuposto a obtenção de vantagem competitiva sustentada. Em outros termos, elas possuem caráter estratégico para a empresa. Elas precisam ser orientadas para o mercado, atendendo às necessidades específicas e únicas dos clientes, de modo que o preço não dependa da concorrência, e difíceis de reproduzir, para que os lucros não sejam afetados pela concorrência (Teece, Pisano e Shuen, 1997). A fim de entender os fatores que determinam as capacidades dinâmicas de uma empresa, Teece, Pisano e Shuen (1997) apresentam três categorias: processos organizacionais, posições e trajetórias. Na seqüência, será descrita cada uma delas conforme contribuição dos autores.

\section{Processos Organizacionais}

Os processos organizacionais estão relacionados com integração/coordenação, aprendizagem e reconfiguração. A integração/coordenação se refere à eficiência e à eficácia na coordenação de recursos internos e externos da empresa. Ela explica por que mudanças tecnológicas menores podem ter impactos significativos na capacidade competitiva da empresa. Um exemplo de capacidade de coordenação é o sistema de produção enxuta, em que até mesmo os vínculos interorganizacionais são modificados. A aprendizagem permite que tarefas sejam mais bem executadas e de forma mais rápida. Os processos de aprendizagem são sociais e coletivos; portanto também ocorrem em função de contribuições 
conjuntas para a resolução de problemas. É importante frisar que os processos de aprendizagem podem ocorrer no nível interorganizacional, dependendo do grau de imbricamento existente entre as organizações que realizam a cooperação, bem como do conteúdo dessa cooperação. A reconfiguração diz respeito à necessidade de reconfigurar a estrutura de ativos da empresa por meio de transformações internas e externas. A capacidade de se reconfigurar e transformar a si mesma é uma habilidade organizacional aprendida. Quanto mais freqüentemente executada, mais facilmente realizada. Para a reconfiguração é importante a habilidade de examinar o ambiente rapidamente.

\section{Posições}

A postura estratégica de uma empresa é determinada não apenas pelos seus processos de aprendizagem, mas também pelos ativos específicos. Tais ativos determinam sua vantagem competitiva em determinado momento. Os tipos de ativos podem ser tecnológicos, complementares (capacidade de comercialização), financeiros (posição de caixa e grau de alavancagem), reputacionais (imagem da empresa e da marca), estruturais (a estrutura formal e informal das organizações e seus vínculos externos possuem implicação importante para a taxa e direção da inovação, bem como as competências e capacidades co-evoluem), ativos institucionais (legislação, políticas públicas etc) e fronteiras organizacionais (grau de integração vertical lateral ou horizontal).

\section{Trajetórias}

A noção de dependência de trajetória indica que a história interessa. Os investimentos prévios de uma firma e o seu repertório de rotinas restringem o seu comportamento futuro. Se muitos aspectos do ambiente de aprendizagem de uma empresa se modificam simultaneamente, a habilidade de definir relações de causa e efeito é confundida, porque as estruturas cognitivas não serão formadas e as taxas de aprendizagem vão diminuir, como resultado disso. A experiência passada de uma empresa condiciona as alternativas que a gerência pode perceber.

Como pôde ser visto pela contribuição de Teece, Pisano e Shuen (1997), a abordagem das capacidades dinâmicas é especialmente relevante para as configurações interorganizacionais. Ao destacar a importância da capacidade de coordenar o uso interno e externo dos recursos da empresa, a teoria das capacidades dinâmicas enfatiza que as competências distintivas dos atores externos, tais como compradores e fornecedores, estão entre os fatores impulsionadores das decisões de desenvolver ou não a cooperação (Lorenzoni e Lipparini, 1999). Também no âmbito das teorias baseadas na competência, a 
visão da empresa baseada no conhecimento considera a habilidade de integrar esforços de diferentes atores tão importantes quanto a capacidade de inovar (Grant apud Lorenzoni e Lipparini, 1999). A capacidade de integrar conhecimento e transformar competências tácitas e explícitas dispersas em um corpo mais amplo de conhecimento organizacional é uma capacidade estratégica fundamental da empresa (Nonaka, 1997; Grant apud Lorenzoni e Lipparini, 1999).

Neste sentido, redes e demais configurações interorganizacionais podem fornecer certa maneira eficaz de organizar a transferência de conhecimento, ou de acessá-lo, em domínios dinamicamente competitivos e em contextos onde o conhecimento complexo é fragmentado e especializado ou cada vez mais baseado na ciência. A capacidade de aprendizagem organizacional é decisiva e uma troca intensa de conhecimento pode ajudar a reforçar o posicionamento estratégico (Lorenzoni e Lipparini, 1999).

Se na abordagem das capacidades dinâmicas, mais importante do que o estoque atual de recursos é a capacidade de acumular e combinar novos recursos em novas configurações capazes de gerar fontes adicionais de rendas (Vasconcelos e Cyrino, 2000), a habilidade de interagir e compartilhar conhecimento com outras empresas é competência organizacional distintiva para as empresas. Especialmente se essas interações contribuem para a construção de competências distintivas em temas como $\mathrm{P} \& \mathrm{D}$, desenvolvimento de novos produtos, definição dos segmentos de mercado em que será posicionado o produto, inovação tecnológica, entre outros. Assim, pode-se dizer que a habilidade de orquestrar diferentes fontes de aprendizagem é vista como intenção estratégica e não como resultado de uma série de estratégias contingentes e não planejadas. Esta habilidade, por si só, é capaz de gerar vantagem competitiva; ela pode ser vista, à luz das capacidades dinâmicas, como capacidade relacional. No caso da Rede PETRO-RS, a capacidade relacional, desenvolvida a partir das interações entre empresas, entre universidades e empresas e entre empresas e Governo, pode ser uma grande fonte de vantagem competitiva.

A construção de parcerias com visão futura parece ser pré-condição essencial do desenvolvimento da capacidade relacional necessária à condução da redefinição das fronteiras no interior de uma rede ou de outro tipo de arranjo interorganizacional. Com o tempo, a capacidade relacional permite aos gerentes reduzir o custo das trocas, otimizar a escolha das estruturas de governança e internalizar conhecimento especializado presente na rede interorganizacional (Lorenzoni e Lipparini, 1999). Por fim, a capacidade relacional emerge como ativo estratégico, tanto para grandes como para pequenas empresas, permitindo flexibilidade na combinação e coordenação dos recursos (Lorenzoni e Lipparini, 1999). 
Distintos modos de governança apóiam, em maior ou menor grau, os diferentes tipos de inovação. Dependendo do tipo de produto, há inovações mais autônomas e inovações mais sistêmicas, que dependem de uma maior articulação com outros atores. Se a estrutura formal e informal das organizações e seus vínculos externos forem considerados dentro de um contexto de relações interorganizacionais, tornase questão relevante investigar quais características estruturais (ou como o modo de governança) da rede podem contribuir para o aumento da capacidade relacional.

\section{Redes para Elevar a Capacidade Inovativa das Empresas}

A palavra rede é, por excelência, interdisciplinar. É possível encontrá-la em disciplinas e campos muito diversos: matemática, geografia, sociologia, economia industrial, física, informática, zoologia etc. No entanto, entre as suas propriedades mais gerais, pode-se reter a idéia de entrelaçamento, imbricamento e malha de relações capazes de capturar informações essenciais. Este capturar informações essenciais guarda relação com dois atributos fundamentais de uma rede: a conectividade, entendida como a capacidade estrutural de facilitar a comunicação sem ruídos entre seus componentes, e a coerência, entendida como a existência de objetivos e interesses compartilhados entre os componentes da rede (Castells, 2000).

Se, por um lado, a capacidade de adaptação e a flexibilidade são pontos fortes para o funcionamento das redes, por outro lado desenvolver orientações, de forma deliberada, para o desenho estratégico destas facilita a sua evolução e a obtenção de uma vantagem sustentada (Lorenzoni e Lipparini, 1999). A rede interorganizacional pode ser vista como mecanismo estratégico para melhorar a vantagem competitiva da empresa. Em sintonia com as trajetórias que fazem parte das capacidades dinâmicas, a rede, enquanto meio de obter recursos e capacidades fora da organização, é criada por um processo dependente de uma trajetória e, portanto, difícil de imitar (Andersson, Forsgren e Holm, 2002).

De forma esquemática, a trajetória de evolução das relações de cooperação pode apresentar quatro estágios (Doz, 1996). No primeiro estágio, são definidas as condições iniciais da cooperação: a definição das tarefas, as rotinas organizacionais dos parceiros, a estrutura de interface (ou como será organizada a interação das empresas ou dos atores) e as expectativas dos parceiros em relação ao desempenho da cooperação e seu comportamento. No segundo estágio, essas condições poderão ou não conduzir a uma aprendizagem em relação ao ambiente competitivo, às tarefas da cooperação, ao processo e às habilidades a serem desenvolvidas e metas a serem atingidas. No terceiro estágio, a aprendizagem 
permite uma reavaliação da cooperação quanto a sua eficiência, adaptabilidade (isto remete diretamente à noção evolucionária da seleção feita pelo mercado) e retorno financeiro. No quarto estágio, a reavaliação conduz a revisão das condições iniciais (aqui se percebe a retomada do caráter deliberado da estratégia do arranjo), a definição das tarefas, as rotinas organizacionais dos parceiros, a estrutura de interface e as expectativas dos parceiros em relação ao desempenho da cooperação e seu comportamento.

Ao considerar uma rede de empresas e demais atores envolvidos no processo de inovação tecnológica, torna-se relevante explorar o conceito de imbricamento (embeddedness). O conceito de imbricamento surge a partir do trabalho de Granovetter (1985), em que ele reconhece a importância das relações pessoais concretas e redes de relações para gerar confiança, estabelecer expectativas, criar e reforçar normas. A noção de imbricamento de Granovetter (1985) pode ser vista como tentativa de introduzir as relações sociais e organizacionais no sistema econômico, tradicionalmente desprezadas tanto pelo mainstream da economia quanto por setores da economia institucional (Coleman, 1990).

De acordo com Granovetter (1985), as relações entre as empresas são mais importantes para trazer ordem à vida econômica do que é suposto pela linha de pensamento "mercado e hierarquia" (Williamson, 1985). Ainda segundo o autor, o imbricamento das relações pode gerar padrões de comportamento esperados que são superiores às relações de autoridade hierárquicas puras no desestímulo ao comportamento oportunista. Embora, para Granovetter (1985), o conceito de imbricamento social presente nas transações econômicas esteja focado na redução do comportamento oportunista, o imbricamento, ao contribuir para a produção de confiança, tende a facilitar a complementaridade de recursos por meio dos conteúdos trocados nas relações de cooperação, especialmente os recursos intangíveis e com elevada ambigüidade causal (Reed e DeFiliippi, 1990). Por meio de relações cooperativas, as empresas trabalham conjuntamente para melhorar coletivamente o desempenho, partilhando recursos e se comprometendo com objetivos comuns (Gnyawali e Madhavan, 2001).

O imbricamento nas redes, resultante da interação de membros de distintas organizações, se desenvolve, com o tempo, de um estado caracterizado por relações de compra e venda para relações baseadas em adaptação e confiança (Andersson, Forsgren e Holm, 2002). Ele enfatiza os laços coesivos como mecanismo para obter informações mais tácitas e difíceis de serem codificadas. Para Andersson, Forsgren e Holm (2002) existe também o imbricamento técnico, definido como a interdependência das empresas no que se refere ao desenvolvimento de produtos e processos de produção. Um alto grau de interdependência técnica significa que as duas ou mais organizações são bastante 
interdependentes em suas atividades técnicas. Tanto o imbricamento empresarial como o técnico estão combinados nas redes de informação e conhecimento de que as empresas se podem valer. Por sua vez, o imbricamento empresarial tem alto impacto positivo sobre o imbricamento técnico.

Nessa linha de raciocínio, Powell, Koput e Smith-Doerr (1996) encontram evidência que relaciona o crescimento das empresas com as suas relações de rede. A habilidade de absorver conhecimento do ambiente depende, entre outras coisas, da rede de relações interorganizacionais que as empresas estabelecem. No mesmo sentido, pode-se dizer que o desenvolvimento de competências está relacionado com esta rede, além de a capacidade relacional ser ela mesma uma competência.

A rede externa com os diversos atores envolvidos no processo de inovação tecnológica ou organizacional pode desempenhar papel crucial como fonte estratégica para o desenvolvimento de competências (Andersson, Forsgren e Holm, 2002). A diversidade de atores com ativos de conhecimento complementares permite que idéias e criatividade sejam coletadas de fora da empresa, podendo aumentar sua habilidade não apenas para reagir à mudança, mas para promovê-la (Lipparini e Sobrero, 1997). Ao cooperar com atores externos, as empresas aumentam a sua habilidade de reorganizar a sua base de conhecimento. Isto porque o aprendizado proporcionado pelas redes também guarda relação com a capacidade de os atores reestruturarem as funções e os conteúdos de suas interações (Lütz, 1997). Em outras palavras, as redes são flexíveis quanto aos seus objetivos e formas de coordenação. Conjuntamente com o imbricamento, um fator importante para a sustentabilidade das redes é a legitimidade ou credibilidade para o emprego de recursos de parte dos atores. Os diversos conteúdos trocados, bem como os processos de interação se podem prontamente desconstituir, se o mecanismo de coordenação da rede perde a sua legitimidade (Human e Provan, 2000). No caso da experiência da Rede PETRORS, a legitimidade foi conferida pela presença do Governo como indutor e facilitador da formação da rede.

Em relação ao papel do Governo (ator muito importante), o incentivo e a atuação na formação de uma rede para o desenvolvimento empresarial podem ser vistos como externalidade positiva. Considerando os custos associados com os estágios iniciais de formação da rede, a busca de parceiros, o esforço de sensibilização das empresas, a construção de confiança e a importância do apoio institucional à cooperação, cumpre ressaltar a participação do Governo como catalisador e organizador da rede. De modo geral, as políticas voltadas ao fortalecimento da inovação e da cooperação têm-se caracterizado por iniciativas como programas de estímulo à cooperação universidade-empresa, programas para a solução de 
problemas específicos enfrentados por pequenas e médias empresas, ao formar redes ou vincular-se a redes e programas voltados à dimensão geográfica de uma rede (OCDE, 2001).

A estrutura deste tipo de rede é bastante flexível e tende a resultar de uma estratégia emergente, construída pelos atores (Mintzberg, 1987), com o mínimo de exigências formais. As políticas voltadas a estas redes estimulam a formação de relações sustentadas de longo prazo e objetivam a criação de modelos organizacionais que ajudam a construir a confiança entre os parceiros da rede. Ao mesmo tempo, há clara percepção de que as instituições de financiamento público ou governos não deveriam tentar gerenciar as relações dentro da rede. Em alguns casos, o apoio administrativo e organizacional, bem como os recursos informacionais, são fornecidos como serviços às redes (OCDE, 2001).

Segundo documento da OCDE (2001), o sucesso de programas de formação ou fortalecimento de redes de capacitação tecnológica depende de alguns fatores. Os resultados da cooperação entre os atores devem ser apropriados pelo conjunto dos atores que integram a rede. Deve haver apoio organizacional e gerencial para a auto-organização dos participantes da rede, tanto pela oferta de financiamentos de longo prazo como pela criação de organizações intermediárias para a gestão da rede, a exemplo das associações empresariais.

\section{Método}

O estudo seguiu a metodologia do estudo de caso por meio da utilização de coleta e análise de dados primários e secundários. No caso dos dados primários, foram realizadas entrevistas semi-estruturadas com os coordenadores da Secretaria Executiva da rede no período de 1999 a 2002, com dois profissionais que participaram da elaboração da concepção e da estrutura organizacional, dos objetivos e da dinâmica de funcionamento da Rede PETRO-RS, com dois representantes da universidade, com duas empresas e um profissional da REFAP. No caso dos dados secundários, foram examinados documentos como o relatório de atividades intitulado Rede Gaúcha de Fornecedores de Base Tecnológica para o Setor de Petróleo e Gás Natural - REDE PETRO-RS - SCT, o documento que apresenta a concepção inicial da rede e o Termo de Referência utilizado na formação da rede.

O roteiro das entrevistas continha perguntas relacionadas à forma como ocorria a cooperação entre as empresas e os demais atores, às distintas etapas de formação da rede, à importância da atuação do Governo do Estado do Rio Grande do Sul 
como facilitador das relações de cooperação, à rede como fonte de aprendizagem dinâmica, às implicações do ingresso das empresas na rede para alavancar sua capacidade tecnológica e, por fim, em que medida ela possibilitou implementar novas e criativas estratégias de penetração de mercado das empresas que nela atuam.

Para a análise dos dados, além da descrição da formação da rede, foi feita uma categorização de acordo com o roteiro e implicações teóricas presentes na teoria das capacidades dinâmicas, para verificar evidências de como a experiência se relacionava com o tema do desenvolvimento das capacidades dinâmicas e em que medida essas capacidades se constituíram como resultado da cooperação entre empresas, universidades, governos e centros tecnológicos.

\section{EXPERIÊNCIA INTERNACIONAL}

Embora única em seu formato, a Rede PETRO-RS foi em parte inspirada em experiências internacionais prévias de políticas públicas destinadas ao fortalecimento da cadeia de suprimento. Já na década de 70, o Governo do Reino Unido, ao detectar uma participação entre 25 e 30\% dos fornecedores locais na cadeia de produção do petróleo, criou um órgão governamental específico para articular os fornecedores com as operadoras, o Offshore Supllies Office (OSO). De acordo com o Memorandum of Understanding (MOU) feito com a United Kingdom Offshore Operators Association (UKOOA), seria empreendido um esforço visando a assegurar, em bases competitivas, justa e plena oportunidade aos fornecedores locais. Essas ações do governo deixaram claro o seu posicionamento com relação a uma política de fortalecimento dos fornecedores locais. Em função disso, em 1995 a participação local no fornecimento de bens e serviços para o setor havia alcançado um patamar de 70\% em relação aos 30\% de duas décadas atrás.

Em 1992 o Reino Unido aboliu o uso do MOU, por considerar as suas empresas competitivas e por pressão da Comunidade Européia, que o considerou discriminatório. Com isso a atuação do OSO se modificou, passando a se concentrar também nos segmentos de refino, transporte e distribuição. Hoje o foco de atuação do OSO é apoiar os fornecedores nacionais na maximização da sua participação no mercado internacional de bens e serviços. Ainda em 1992 foi criado o Cost Reduction for the New Era (CRINE), com representação do governo, das operadoras e dos fornecedores. O objetivo inicial do CRINE foi obter redução de 30\% nos custos de produção, por meio de ações baseadas na cooperação entre os atores do setor. 
Como resultado das ações desse programa, em 1995 a cadeia obteve redução de $47 \%$ no custo de investimentos (CAPEX) e de 30\% no custo de operações (OPEX). Além disso, e não menos importante, obteve-se a formação de uma rede de fornecedores com grande espírito de cooperação e alianças operacionais.

No Canadá a regulação das atividades petrolíferas é realizada por órgãos estaduais, como, por exemplo, o New Scotia Offshore Petroleum Board, responsável pelas atividades offshore na província de Nova Escócia. Este órgão visa a assegurar justa e plena participação das empresas locais, especialmente do Estado, no fornecimento de bens e serviços para o setor. Como exemplo do controle exercido pelo órgão regulador sobre as operadoras, cumpre citar que o órgão deve ser informado sobre a pré-qualificação de fornecedores, execução de concorrências para aquisição de bens e serviços e assinatura de contratos e colocação de compras. A operadora deve receber aprovação do órgão para todas as atividades relacionadas com a aquisição de bens e serviços, cujo valor exceda \$50.000 dólares canadenses (US\$33.000).

Estes dois exemplos ilustram iniciativas de uma ação mais proativa de parte de governos para a elevação da competitividade de indústrias de alto valor agregado, com forte potencial de inovação tecnológica.

\section{REDE PETRO-RS}

Surgida em 1999 como resultado de uma ação da Secretaria de Ciência e Tecnologia (SCT) do Governo do Estado do Rio Grande do Sul para fortalecer a cadeia de suprimento da indústria do petróleo e gás, particularmente a cadeia de fornecedores da PETROBRÁS, a Rede PETRO-RS constitui uma articulação pioneira no Brasil. Reunindo uma diversidade de atores, como universidades, empresas, centros tecnológicos e órgãos do Governo (Secretarias de Estado e bancos públicos), a Rede PETRO-RS visa à promoção do desenvolvimento da indústria de base tecnológica do Estado com foco nos setores de petróleo, gás natural, energia e mineração. A rede respondeu à necessidade de maior cooperação entre empresas e universidades com foco no desenvolvimento de tecnologia com vistas à inovação em produtos e processos.

Em sua fase embrionária, a rede já focalizava o desenvolvimento de tecnologia e produtos. A concepção preliminar da constituição de um espaço para maior articulação entre universidades, empresas e governo teve por base a demanda trazida por um grupo de empresas, que procurou a SCT para apoio no desenvolvimento de produtos para a PETROBRÁS. Diante da dificuldade de 
atender a um pedido feito pela PETROBRÁS de cabos de fibras sintéticas para sustentação de plataformas em águas profundas, houve o contato entre empresas que pudessem ter o mesmo tipo de problema. Pode-se dizer que a principal motivação para a formação da rede de parte das empresas foi a capacitação em desenvolvimento de produtos, melhoria de processos e marketing proporcionada pela rede para poder entrar no promissor mercado de fornecimento da indústria de petróleo e gás. Para as universidades, a principal motivação foi a possibilidade de ter acesso a fundos para o desenvolvimento de suas pesquisas.

Atualmente, a rede conta com a participação de 126 empresas, 91 laboratórios e centros de pesquisas de 7 universidades do Rio Grande do Sul. Além disso, são parceiros institucionais da rede, a Secretaria de Desenvolvimento e Assuntos Internacionais do Governo do Rio Grande do Sul (SEDAI), a Financiadora de Estudos e Projetos (FINEP), o Banco do Estado do Rio Grande do Sul (BANRISUL), o SEBRAE/RS, a FIERGS, a FEDERASUL, o Banco Regional de Desenvolvimento Econômico (BRDE) e a própria PETROBRÁS, por meio da Refinaria Alberto Pasqualini (REFAP). Merece destaque o fato de que a rede consegue reunir empresas, governo, associações empresariais, universidades e centros tecnológico, além de clientes. Entre os seus principais objetivos, está a ampliação das oportunidades de mercado na cadeia de fornecimento da indústria de petróleo e gás, o desenvolvimento de capacidade tecnológica adequada às necessidades das empresas produtoras de petróleo, com vistas ao mercado nacional e internacional, e a aproximação das empresas gaúchas dos centros de pesquisa locais e das agências de fomento, visando ao desenvolvimento ou consolidação de tecnologias de ponta, com alto valor agregado.

Com exceção do fundo setorial CT-PETRO com a finalidade de estimular a pesquisa aplicada, não havia ação especifica de fortalecimento da cadeia de suprimento da indústria de petróleo e gás. O caráter estratégico dessa indústria se revela tanto nos investimentos da ordem de 100 bilhões de dólares anunciados em 1998 pelas maiores empresas da América Latina (PETROBRÁS, PDVSA e PEMEX), quanto na sua importância, considerando ser uma indústria intensiva de capital, para a competitividade das médias e pequenas empresas gaúchas, além do aumento da capacidade tecnológica do Estado, com o envolvimento de universidades e centros tecnológicos. Atualmente, o índice médio de nacionalização dos grandes contratos firmados até hoje e estimado para os próximos anos é de 40\% (Balanço Setorial da Gazeta Mercantil, 2002), o que revela grande oportunidade para a indústria nacional, quando se considera o potencial de nacionalização. Na sua maioria, as empresas que integram a rede são dos ramos eletromecânicos: motores elétricos, bombas, válvulas, torres de destilação etc; eletroletrônico e metalurgia, como caldeirarias. Para a seleção das empresas que ingressam na rede, há dois critérios fundamentais: só são 
admitidas empresas de bens ou serviços, não havendo a presença de representantes de empresas, e empresas que tenham plantas industriais ou escritórios no Rio Grande do Sul.

Na sua estrutura funcional, a rede possui uma Secretaria Executiva e um Grupo Gestor, com a participação do BANRISUL, BRDE, REFAP, FINEP, universidades e empresas, com a finalidade de gerenciar o seu processo de estruturação. A Secretaria Executiva é formada por dois coordenadores: um coordenador empresarial e um coordenador representante do Governo do Estado. A rede possui estrutura bastante flexível, que se reúne de forma ad hoc, considerando o tipo de ação coletiva a ser empreendida. Por exemplo, diante de uma oportunidade de negócio identificada a partir de uma atividade de promoção comercial, são feitas reuniões com empresas com produtos ou serviços capazes de atender àquela demanda de mercado em particular. O mesmo ocorre em relação à cooperação universidade-empresa diante da necessidade de desenvolvimento de determinados produtos. A principal função da Secretaria Executiva é o repasse sistemático de informações sobre oportunidades de negócios, possibilidades de financiamento, editais com recursos para pesquisa aplicada, organização e reuniões e atividades de promoção comercial, bem como o fortalecimento dos contatos institucionais da rede dentro e fora do Governo. Na Figura 1 segue um esquema representativo da estrutura e dos atores integrantes da rede.

\section{Figura 1: Atores da Rede PETRO-RS e seus Vínculos}

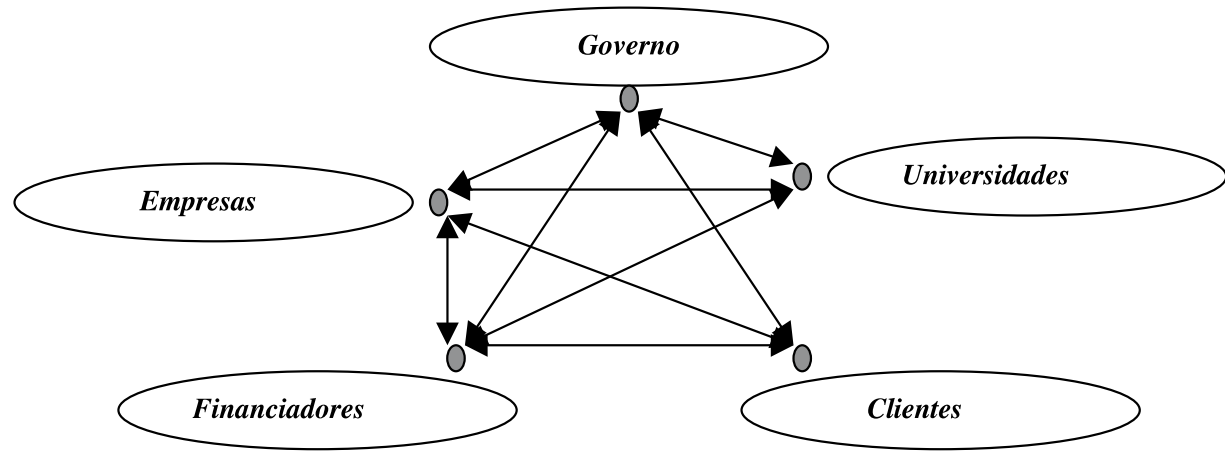

\section{A Rede PETRO-RS e o Desenvolvimento das Capacidades DinÂmicas NAS EMPRESAS}

Se for considerado, conforme Prahalad e Hamel (1990), que as competências 
essenciais oferecem acesso a uma ampla variedade de mercados, contribuem de maneira significativa para os benefícios percebidos dos clientes do produto final, são difíceis de serem imitadas e requerem profundo comprometimento em trabalhar além das fronteiras organizacionais, pode-se dizer que a Rede PETRORS possibilitou o desenvolvimento de competências para as empresas que a integram. A título de exemplo, com base na cooperação universidade-empresa proporcionada pelo espaço da rede, uma empresa fabricante de cordas e cabos sintéticos pôde levar adiante um projeto de desenvolvimento de cabos de ancoragem de plataformas em águas profundas. No mesmo sentido, outra empresa em cooperação com um dos laboratórios que fazem parte da rede foi capaz de desenvolver um gancho fundido a ser utilizado nos processos de prospecção de petróleo. Para além da cooperação universidade-empresa, pode-se mencionar um projeto para o desenvolvimento de tecnologia em que geradores a gás de pequeno porte foram desenvolvidos como resultado de atuação conjunta entre uma empresa produtora de equipamentos de controle, proteção e distribuição de processos industriais e o Centro de Pesquisas (CENPES) da PETROBRÁS.

Sendo a PETROBRÁS uma das principais empresas de petróleo no mundo e estando à altura dos melhores competidores internacionais, as competências e a capacidade tecnológica demandadas de seus fornecedores criam condições para a inserção das empresas da Rede PETRO-RS no mercado global de fornecedores da indústria de petróleo e gás. Ao estabelecerem relações mais próximas com a PETROBRÁS, além das relações de mercado stricto sensu, essas empresas têm acesso a informações qualificadas, que contribuem para o seu processo de adaptação e reconfiguração de habilidades organizacionais necessárias para a obtenção de vantagem competitiva sustentada na cadeia de suprimento. Em outros termos, os recursos informacionais obtidos por meio da rede contribuem para o desenvolvimento das capacidades dinâmicas das empresas. Vale lembrar que tal aproximação dificilmente poderia ocorrer sem a existência da rede com a participação do Governo. Tendo em vista a intensidade dos investimentos realizados no setor, muitas empresas da rede passaram a considerar o fornecimento para a indústria do petróleo e gás como o principal foco de mercado. Isso confere um caráter estratégico na gestão e desenvolvimento de recursos destinados a esse segmento de mercado. Diante do potencial de mercado revelado pelas atividades de promoção comercial realizadas pela rede, muitas empresas passam a redefinir suas estratégias, bem como quais capacidades devem ser internalizadas.

A rede constituiu uma espécie de mecanismo de coordenação de recursos externos às empresas capazes de potenciar os seus próprios recursos. Tais recursos vão desde informações qualificadas sobre o mercado, um trabalho de inteligência competitiva, como destacado por um dos membros da rede, até o uso de equipamentos e conhecimento científico presentes nas universidades. Isto não 
significa que todas as empresas não tinham experiência prévia de cooperação com universidades, mas que essa cooperação se tornou muito mais sinérgica a partir da existência da rede.

A cooperação no interior da rede é puxada pelo mercado, o que confere um foco empresarial necessário para a inovação tecnológica, considerando o conceito schumpeteriano de que inovação constitui o desenvolvimento tecnológico validado pelo mercado. Como foi visto na revisão das capacidades dinâmicas, as redes podem fornecer uma maneira eficaz de organizar a transferência de conhecimento, ou de acessá-lo; os três anos de existência da Rede PETRO-RS apóia tal assertiva. Como espaço de coordenação entre diferentes atores, ela tem a habilidade de orquestrar diferentes fontes de informação e conhecimento. Uma característica comum dos processos de criação de conhecimento bem-sucedidos é o vinculo explícito entre a empresa e as fontes de conhecimento disponíveis fora dela (Eisenhardt e Martin, 2000). Tal processo tende a se tornar uma intenção estratégica por parte das empresas. Já existem empresas que estão formando consórcios para o desenvolvimento de produtos.

No que se refere ao imbricamento proporcionado pela rede, um dos entrevistados declarou que "ela qualificou a relação de nossa empresa com o mercado”. A presença do Governo facilitou o acesso às camadas gerenciais com maior poder de decisão dentro da PETROBRÁs, conferindo a legitimidade e a densidade institucional necessárias. Isto explica por que o acesso a informações mais qualificadas sobre clientes e mercado proporcionado pelas relações e parcerias estabelecidas pela rede dificilmente poderia ser obtido por uma empresa isoladamente. Dada a sua dimensão institucional, a rede possibilitou que muitas empresas tivessem contato com gerentes e diretores da PETROBRÁS. Em uma reunião com o gerente de compras da PETROBRÁS, pôde-se identificar que a empresa mostrava preocupações com a segurança operacional. Esse tipo de informação fez com que empresas tivessem mais cuidados com a linha de operação e assistência técnica, para proporcionar sempre uma pronta resposta vital para a segurança operacional. As reuniões articuladas pela rede com a alta gerência da PETROBRÁS permitiram conhecimento mais detalhado das oportunidades daquilo que se pode fazer. Apesar disso, um dos desafios postos é a estruturação de uma área de inteligência de mercado, com estímulo para troca de informações mais efetiva entre os seus membros. Duas ações nesse sentido seriam o fechamento de parte do site da rede para circulação de informações restritas aos seus membros e a criação de chat para rodadas de negócios e comunicação mais freqüente entre empresas localizadas em diferentes pontos do Estado.

O imbricamento entre as empresas da rede também permite que as prospecções de mercado, feitas por uma empresa, sejam estendidas a outras empresas 
produtoras de bens complementares. Por exemplo, diante de uma oportunidade de negócio na Bolívia, uma empresa passou a ser uma espécie de gerente da rede para prospectar e aprofundar o conhecimento daquela oportunidade para as demais empresas da rede, ou seja, a empresa passou a coordenar os contatos naquele mercado, o que possibilitou a presença junto ao cliente de forma cooperada.

Como forma de articulação e melhor relacionamento entre políticas públicas e empresas, a rede precisa institucionalizar-se, para que mudanças no Governo não representem o fim desse tipo de política pública. Sobre isso, um dos entrevistados declarou que é necessário que exista entendimento dentro do Governo em relação à importância da rede como política permanente. Para além da cooperação interempresarial e da cooperação universidade-empresa, a rede constituiria espaço de articulação e implementação de políticas públicas. Conjuntamente com a integração e diálogo mais profícuo entre as diferentes políticas públicas voltadas ao desenvolvimento industrial e tecnológico, a experiência da rede abre caminhos para a participação efetiva das empresas dos demais atores na construção dessas políticas. A seguir, é apresentada uma relação das principais realizações da Rede PETRO-RS.

. Em 2000, foram desenvolvidos 11 projetos no Rio Grande do Sul de inovação tecnológica por meio de parcerias entre empresas e universidades gaúchas, financiados pelo CTPetro, sendo que, destes, 3 foram articulações diretas da Rede PETRO-RS.

- Desenvolvimento de equipamentos para uma maior nacionalização do fornecimento da PETROBRÁS resultante da cooperação entre empresas e universidades que integram a rede.

. Participação das empresas em feiras organizadas pela rede. Merecem destaque a Rio Oil \& Gas Expo 2002, a Argentina Oil \& Gas Expo 2001 e a Rio Oil \& Gas and Conference 2000.

- Missões internacionais para prospecção do mercado internacional com viagens à Bolívia e à Venezuela.

- Projeto Visitas, em que são agendadas visitas em diferentes empresas e laboratórios que têm a oportunidade de mostrar a sua produção, estabelecer parcerias entre o setor acadêmico e empresarial para o desenvolvimento de tecnologia, fechar negócios e interagir com os demais membros da rede.

- Programa de capacitação de subfornecedores da cadeia produtiva do petróleo e gás. O programa envolve 396 horas de treinamento e 16.282 horas de consultoria nas áreas de gestão estratégica, mercadológica e de produção para cada uma das empresas participantes. 
Retomando as categorias das capacidades dinâmicas, o Quadro 1 mostra como essas categorias se apresentam no contexto da Rede PETRO-RS. Espera-se que essa sistematização ajude a compreender melhor por que esse tipo de arranjo contribui para o desenvolvimento das capacidades dinâmicas.

\section{Quadro 1: Capacidades Dinâmicas na Rede PETRO-RS}

\begin{tabular}{|l|l|}
\hline Capacidades dinâmicas & Como se apresentam \\
\hline Processos organizacionais & $\begin{array}{l}\text { Muitas empresas se modificaram do ponto de vista } \\
\text { tecnológico e de mercado, a partir do seu ingresso na } \\
\text { rede. Esta reconfiguração ocorreu a partir das } \\
\text { oportunidades de mercado identificadas pelas ações } \\
\text { de promoção comercial conjunta. De outra parte, o } \\
\text { estreitamento das relações com as universidades e } \\
\text { mesmo outras empresas produtoras de bens } \\
\text { complementares propiciou processos de } \\
\text { aprendizagem para a criação de recursos. A } \\
\text { cooperação estimulada pela rede também contribui } \\
\text { para uma nova forma de enxergar a competição e as } \\
\text { estratégias da empresa. As interdependências são } \\
\text { mais bem potenciadas. }\end{array}$ \\
\hline Posições & $\begin{array}{l}\text { A rede proporcionou às empresas, por meio das feiras } \\
\text { e missões comerciais internacionais, maior } \\
\text { capacidade de comercialização e melhor } \\
\text { conhecimento do mercado. Ao incorporar instituições } \\
\text { financeiras como parceiras, ela tornou o mecanismo } \\
\text { de financiamento muito mais claro e acessível para as } \\
\text { empresas. Além disso, a rede constitui fonte de } \\
\text { credibilidade para muitas empresas. A conjunção } \\
\text { desses e outros fatores influencia no posicionamento } \\
\text { das empresas que estão na rede. }\end{array}$ \\
\hline $\begin{array}{l}\text { Em alguns casos, a rede teve condiçães de potenciar } \\
\text { as trajetórias das empresas, suas rotinas e e } \\
\text { competências, para atender a um mercado } \\
\text { inteiramente novo, como foi o caso da experiência do } \\
\text { gancho fundido, descrita anteriormente. }\end{array}$ \\
\hline Trajetórias
\end{tabular}

\section{Conclusão}

A capacidade tecnológica da indústria brasileira parece estar diretamente relacionada com o desenvolvimento da pesquisa aplicada voltada à melhoria da competitividade das empresas. Isso é especialmente válido diante de ambiente em que a inovação tecnológica está cada vez mais baseada na ciência, demandando volume crescente de recursos em termos de P\&D. Tendo em vista a importância crescente da inovação tecnológica para a construção e manutenção de vantagem competitiva sustentada e, de outro lado, a necessidade de as empresas buscarem 
a cooperação como forma de desenvolver recursos únicos e criadores de valor, é fundamental o surgimento de iniciativas que facilitem a cooperação e a articulação dos principais atores do processo de inovação: empresas, universidades, instituições financeiras, centros tecnológicos etc. A criação de valor e a conseqüente validação da tecnologia pelo mercado, condição para que a nova tecnologia se torne uma inovação, são enormemente facilitadas quando o desenvolvimento tecnológico é puxado pelas necessidades objetivas do mercado (pulled technology). A inclusão da PETROBRÁS como parceira, principal cliente dos produtos oferecidos à indústria do petróleo e gás pelas empresas da Rede PETRO-RS, constitui elemento facilitador deste tipo de desenvolvimento tecnológico com foco no mercado e nas potencialidades de desenvolvimento da competitividade sistêmica nacional.

Como muitas das empresas que integram a rede possuem foco estratégico na cadeia de suprimento da indústria do petróleo e gás, não apenas as informações e recursos trocados por meio da rede, mas o planejamento das suas próprias ações passa a ter interdependência com as estratégias individuais de cada empresa. Embora ainda seja relativamente cedo para uma explicação teórica da experiência da Rede PETRO-RS, pode-se dizer que ela contém elementos cruciais para o desenvolvimento de competências que garantam vantagem competitiva sustentada para as empresas que a integram. Tais elementos são o estímulo e o financiamento ao desenvolvimento de novos produtos, a coordenação de ações e recursos com vistas a um objetivo comum, isto é, o posicionamento estratégico na cadeia de suprimento da indústria do petróleo e gás em nível nacional e internacional, visando a um maior conhecimento do mercado e a uma melhor capacitação organizacional das empresas.

Da mesma forma, a experiência contribui para a construção e execução de políticas públicas indutoras e facilitadoras da inovação tecnológica, capazes de estimular a atuação dos diversos atores envolvidos no processo.

Pelo que foi possível evidenciar da experiência da Rede PETRO-RS, os resultados se concentram tanto na criação de conhecimento para o desenvolvimento de novos produtos, como na abertura de novos mercados. Nesse sentido, tais resultados expressam tanto o desenvolvimento de competências tecnológicas, que se referem às bases de conhecimento científico e tecnológico e às rotinas necessárias para a sua aplicação, quanto o desenvolvimento de competências organizacionais, que se referem ao conhecimento e rotinas da governança e coordenação das interações sociais, dentro e fora das organizações (Coriat e Dosi, 2002).

A experiência da rede é condizente com a assertiva de que a aprendizagem por absorção também depende diretamente dos recursos de cada empresa. Foi possível 
verificar que as empresas que desenvolvem atividades inovadoras tendem a absorver mais o conhecimento e a informação obtidos com a participação na rede.

Apesar de avanços importantes proporcionados pela rede, a cooperação entre as empresas ainda pode ser bastante incrementada. A rede também necessita de coordenação mais consolidada junto aos demais atores, para reduzir sua dependência em relação às mudanças de Governo. Ainda é necessário que ela desenvolva mecanismos que possibilitem maior interconectividade dos seus membros, fortalecendo o imbricamento e facilitando o desenvolvimento de relações de confiança entre os diversos atores envolvidos. Do ponto vista teórico, o imbricamento e a criação de relações de confiança são importantes para a transferência de conhecimento tácito, um tipo de conhecimento mais presente nas tecnologias emergentes, cujo nível de incerteza é maior.

O resultado disto seria maior sinergia na troca de recursos. Maior cooperação entre as empresas da rede possibilitará a atuação conjunta delas no mercado de petróleo e gás, potenciando as suas complementaridades. Com isso as empresas podem desenvolver atividades criadoras de valor que as tornem ainda mais competitivas em face de competidores poderosos que atuam em âmbito internacional.

Artigo recebido em 21.07.2003. Aprovado em 01.12.2003.

\section{REFERÊNCIAS BIBLIOGRÁFICAS}

ANDERSSON, U.;

FORSGREN, M.;

HOLM, U.

The strategic impact of external networks: subsidiary performance and competence development in the multinational corporation. Strategic

Management Journal, v. 23, p. 979996, 2002.

CASTELLS, M.

A sociedade em rede. Rio de Janeiro: Paz e Terra, 2000.
CHISTIENSEN, J. F.

Analyzing the technology base of the firm. In: FOSS, N. (Ed.). Towards a competence theory of the firm. London: Routledge, 1996.

COHEN, W. ;

LEVINTHAL, D.

Absorptive capacity: a new perspective on learning and innovation. Administrative Science Quarterly, v. 35, n. 1, p. 128-153, 1990. 
COLEMAN, J. S.

Foundations of social theory. Cambridge, MA: Belknap Press, 1990.

CORIAT, B.;

DOSI, G.

The nature and accumulation of organizational competences/ capabilities. Revista Brasileira de Inovação, v. 1, n. 2, jul./dez. 2002.

DOSI, G.

The nature of the innovative process in technical change and economic theory. In: DOSI, G. et al. London: Pinter, 1988.

DOSI, G.;

MARENGO, L.

Some elements of an evolutionary theory of organizational competences. In: RICHARD, W. (Ed.). Evolutionary concepts in contemporary economics. Ann Arbor: University of Michigan Press, 1994.

DOZ, Y. L.

The evolution of cooperation in strategic alliances: initial conditions or learning processes. Strategic Management Journal, v. 17, p. 5583, 1996.

EISENHARDT, K.;

MARTIN, J.

Dynamic capabilities: what are they? Strategic Management Journal, v. 21, p. 1105-1121, 2000.

GNYAWALI, D. R.;

MADHAVAN, R.

Cooperative networks and competitive dynamics: a structural embeddedness perspective. Academy of Management, v. 26, n. 3, p. 431445, 2001.
GRANOVETTER, M.

Economic action and social structure: the problem of embeddedness. American Journal of Sociology, v. 91, n. 3, p. 481-510, 1985.

HUMAN, S.;

PROVAN, K.

Legitimacy building in the evolution of small firm multilateral networks: a comparative study of success and demise. Administrative Science Quarterly, v. 45, n. 2, p. 327-365, 2000.

\section{LIPPARINI, A.;}

SOBRERO, M.

Co-ordinating multi-firm innovative processes: entrepreneur as catalyst in small-firm networks. In: EBERS, M. (Ed.). The formation of interorganizational networks. Oxford: Oxford University Press, 1997.

LORENZONI, G.;

LIPPARINI, A.

The leveraging of interfirm relationships as a distinctive organizational capability: a longitudinal study. Strategic Management, v. 20, p. 317-338, 1999.

\section{LÜTZ, S.}

Learning through intermediaries: the case of interfirm research collaboration. In: EBERS, M. (Ed.). The formation of interorganizational networks. Oxford: Oxford University Press, 1997. 
MCGEE, J. E.;

DOWLING, M. J.;

MEGGINSON, W. L.

Cooperative strategy and new venture performance: the role of business strategy and management experience. Strategic Management Journal, v. 16, p. 565-580, 1995.

MINTZBERG, $\mathrm{H}$. Crafting strategy. Harvard Business Review, v. 57, n. 4, 1987.

NONAKA, I.;

TAKEUCHI, H.

A criação de conhecimento na empresa. Rio de Janeiro: Campus, 1997.

\section{OCDE.}

Innovative networks: cooperation in national innovation systems. Paris: OCDE Publications, 2001.

POWELL, W.;

KOPUT, K. W.;

SMITH-DOERR, L.

Interorganizational collaboration and the locus of innovation: networks of learning in biotechnology. Administrative Science Quarterly, v. 41, n. 1, p. 116-145, 1996.
PRAHALAD, C. K.;

HAMEL, G.

The core competence of the corporation. In: FOSS, N. (Ed.). Resources, firms and strategies. Oxford: Oxford University Press, 1997.

REED, R.;

DEFILLIPPI, R.

Causal ambiguity, barriers to imitation and sustainable competitive advantage. Academy of Management Journal, v. 15, n. 1, p. 88-102, 1990.

TEECE, D. J.;

PISANO, G.;

SHUEN, A.

Dynamic capabilities and strategic management. Strategic Management Journal, v. 18, n. 7, p. 509-533, 1997.

VASCONCELOS, F. C.;

CYRINO, A. B.

Vantagem competitiva: os modelos teóricos atuais e a convergência entre estratégia e teoria organizacional. Revista de Administração de Empresas, v. 40, n. 4, p. 20-37, out./ dez. 2000.

WILLIAMSON, O.

The institutions of capitalism. Cambridge, MA: Belknap Press, 1985. 